\title{
Time-Resolved Recombination Analysis in Kesterite Polycrystalline Thin Films and Photovoltaic Devices with One-Photon and Two-Photon Excitation
}

Darius Kuciauskas, * Ingrid Repins, Ana Kanevce, Jian V. Li, Pat Dippo, and Carolyn L. Beall

National Renewable Energy Laboratory, 15013 Denver West Parkway, Golden, CO 80401-3305, USA

\begin{abstract}
Minority carrier lifetime, $\tau_{\mathrm{B}}$, is one of the key metrics for polycrystalline solar cell absorbers. Based on different spatial carrier-generation profiles obtained using onephoton and two-photon excitation (1PE and 2PE, respectively), we developed a new approach to determine $\tau_{\mathrm{B}}$ in polycrystalline thin films. By comparing time-resolved photoluminescence data measured with $1 \mathrm{PE}$ and $2 \mathrm{PE}$, we extract $\tau_{\mathrm{B}}$ and surface recombination velocity $S$, and resolve charge separation at the pn junction. For coevaporated kesterite $\left(\mathrm{Cu}_{2} \mathrm{ZnSnSe} 4\right)$ absorbers, we find $\mathrm{S}=(0.8-2.1) \times 10^{4} \mathrm{~cm} \mathrm{~s}^{-1}$ and $\tau_{\mathrm{B}}=7.0 \pm 0.5$ ns. For corresponding photovoltaic devices, charge separation occurs in $\leq 2$ ns.

*Darius.Kuciauskas@nrel.gov, tel.303-384-6572, fax 303-384-7600
\end{abstract}




\section{Introduction}

Interest in kesterite $\left(\mathrm{Cu}_{2} \mathrm{ZnSnS}_{\mathrm{x}} \mathrm{Se}_{4-\mathrm{x}}\right.$ and related alloys) photovoltaics is primarily driven by the lower cost and Earth abundance of the constituent elements $[1,2]$. However, kesterite photovoltaic (PV) solar cells typically have lower opencircuit voltage $\left(\mathrm{V}_{\mathrm{OC}}\right)$ than expected based on the material bandgap, Eg. Short minority-carrier lifetime, $\tau_{\mathrm{B}}$, is thought to be an important contributor to $\mathrm{V}_{\mathrm{OC}}$ loss [3]. Although there are several approaches for the analysis of $\tau_{\mathrm{B}}$ [4], only timeresolved photoluminescence (TRPL) has been applied as a direct measure of recombination in kesterite thin films and PV devices [5-17]. As illustrated in Scheme I, laser pulses in a traditional one-photon excitation ("1PE") TRPL measurement are absorbed close to the surface, and therefore, the PL signal is mostly emitted from the surface region of the polycrystalline film. Thus, with 1PE, it might not be possible to distinguish bulk and surface recombination.

Scheme I. Illustration of one-photon and two-photon excitation (1PE and 2PE, respectively) in thin film materials. Shaded area represents depth at which excitation light is attenuated to $10 \%$ of its initial intensity.
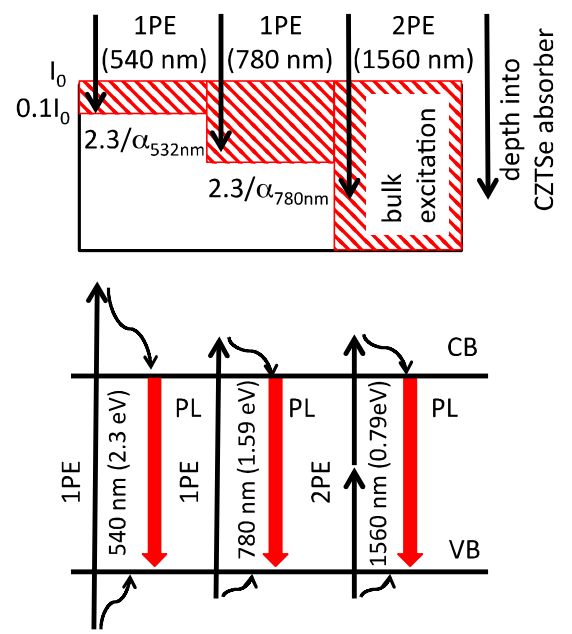
We employ a new approach to analyze minority-carrier dynamics and recombination in polycrystalline $\mathrm{Cu}_{2} \mathrm{ZnSnSe}_{4}$ (CZTSe) thin films and PV devices. By varying excitation photon energy so that electron-hole pairs are created either $<0.15 \mu \mathrm{m}$ from the interface (540-nm excitation) or uniformly in the polycrystalline film (two-photon excitation, 2PE) [18,19], we independently analyze recombination at the surface and in the bulk to determine surface recombination velocity, $\mathrm{S}$, and $\tau_{\mathrm{B}}$. With $2 \mathrm{PE}$, the excitation photon energy is smaller than the bandgap, and simultaneous absorption of two photons is necessary to create an electron-hole pair (Scheme I). Lower two-photon absorption probability (in comparison with onephoton absorption) ensures more uniform initial carrier distribution in the thin polycrystalline film. By using 2PE TRPL, we are also able to directly observe charge separation in CdS/CZTSe polycrystalline PV devices.

\section{Materials and Methods}

\subsection{Samples}

A brief summary of the growth of CZTSe films and PV devices used in this study is recounted below, while more a more detailed description can be found in the literature.[6,7] First, soda-lime glass substrates were coated with a 1- $\mu \mathrm{m}$ Mo back contact. Then, $1.5 \mu \mathrm{m}$ of slightly Cu-poor and Zn-rich CZTSe was coevaporated while the substrate was maintained at $510^{\circ} \mathrm{C}$. Upon removal from the

growth chamber, the sample was cut into several pieces. Those pieces that received no additional processing are termed "absorbers" or "polycrystalline films" in the remainder of the study. The device structure was completed on other pieces, 
utilizing the typical buffer and window layers the commonly used for both CZTSe and CIGS photovoltaics. These layers, in order of deposition, consist of $500 \AA$ A bathdeposited CdS, $1000 \AA ̊$ resistive $\mathrm{ZnO}, 1000 \AA ̊$ conductive $\mathrm{ZnO}$ :Al, and metal grids to aid in current collection.

The absorber studied in this paper produced devices with the following current-voltage parameters, without antireflective coating: total-area AM1.5 power conversion efficiency $=8.3 \%$, open-circuit voltage $=373 \mathrm{mV}$, fill factor $=66.5 \%$, and short-circuit current $=33.4 \mathrm{~mA} / \mathrm{cm}^{2}$.

\subsection{Measurements}

Excitation was provided by the optical parametric amplifier pumped by a Yb:KGW laser with 1.1-MHz repetition rate and pulse length of $0.3 \mathrm{ps}$ (Orpheus/Pharos, Light Conversion). Excitation wavelength was $540 \mathrm{~nm}$ (similar to some earlier TRPL measurements on kesterites) [5,8,11-17], $780 \mathrm{~nm}$ [10], and 1560 $\mathrm{nm}$. Excitation at $1560 \mathrm{~nm}(0.79 \mathrm{eV})$ is below the bandgap of the material used in this study $\left(\mathrm{E}_{\mathrm{g}} \approx 1 \mathrm{eV}\right)[6]$ and absorption of two photons is necessary to create an electron-hole pair. Because 1560-nm photon energy is half that of 780-nm photons, excited states created with $2 \mathrm{PE}$ at $1560 \mathrm{~nm}$ are expected to correspond to excited states obtained with 1PE at $780 \mathrm{~nm}$. A multimode-optical-fiber-based 1PE and 2PE TRPL spectrometer for time-correlated single-photon counting was described [18]. Excitation spot diameter of $0.2 \mathrm{~mm}$ in $1 \mathrm{PE}$ and $0.02 \mathrm{~mm}$ in $2 \mathrm{PE}$ was estimated by using calibrated pinholes and assuming a Gaussian-shaped excitation beam. Spectrally integrated photoluminescence was measured with 1150-nm long-pass filters and a Hamamatsu R5509-42 photomultiplier. When PL signal intensity was 
low, the background scattering was subtracted from the data. Instrumental response function (IRF) had a full width at half maximum (FWHM) of $0.35 \mathrm{~ns}$. Deconvolution of IRF was applied to resolve lifetimes $\geq 0.1 \mathrm{~ns}$. The same setup was used to measure total PL intensity, which was determined by integrating TRPL transients over time.

\section{Results and Discussion}

\subsection{One-photon excitation (1PE) TRPL decays for CZTSe polycrystalline film} and PV device

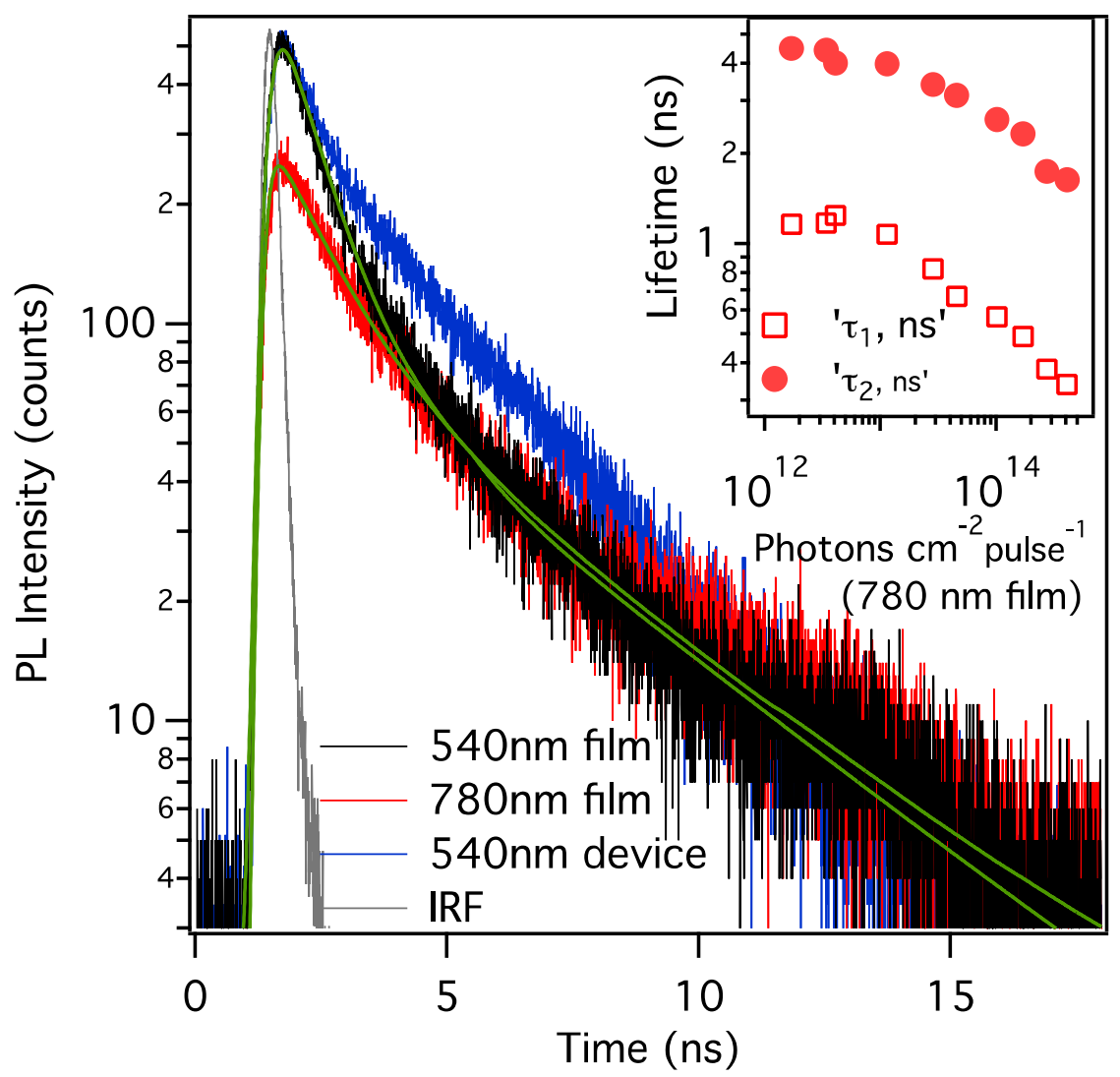

Fig. 1. 1PE TRPL decays measured using excitation at $540 \mathrm{~nm}$ (black, data for polycrystalline film; blue, data for corresponding PV device) and $780 \mathrm{~nm}$ (red, data for polycrystalline film). Excitation intensity was $2.3 \times 10^{12}$ photons $\mathrm{cm}^{-2}$ pulse-1 $^{-1}$ $(540 \mathrm{~nm})$ and $1.7 \times 10^{12}$ photons $\mathrm{cm}^{-2}$ pulse-1 $(780 \mathrm{~nm})$. Instrumental response function is shown in grey; results of two-exponential fitting of the data in green. 
Inset shows lifetime $\tau_{1}$ and $\tau_{2}$ intensity dependence determined with $780 \mathrm{~nm}$ excitation for polycrystalline film.

Fig. 1 shows TRPL decays measured on a polycrystalline film with excitation at $540 \mathrm{~nm}$ (black) and $780 \mathrm{~nm}$ (red) using low laser power. According to Beer's law, light is attenuated to $10 \%$ of its intensity at the depth of $2.303 / \alpha$, which is only 0.14 $\mu \mathrm{m}$ when 540-nm excitation is used and about four times larger, $0.56 \mu \mathrm{m}$, when $780-\mathrm{nm}$ excitation is used. (Absorption coefficients are $\alpha_{540 \mathrm{~nm}}=1.7 \times 10^{5} \mathrm{~cm}^{-1}$ and $\left.\alpha_{780 \mathrm{~nm}}=4.1 \times 10^{4} \mathrm{~cm}^{-1}[20].\right)$ Because polycrystalline film is $\approx 1.5 \mu \mathrm{m}$ thick and surface recombination velocity, $\mathrm{S}$, is not known, it is not clear if 1PE TRPL decays measured on thin films represent surface recombination, bulk recombination, or some combination of these two processes. Carrier separation due to surface band bending [21] might also contribute to observed TRPL decays when excitation is limited to the surface region. The initial carrier concentration (estimated assuming 2.303/ $\alpha$ absorption depth) for decays in Fig. 1 was $1.7 \times 10^{17} \mathrm{~cm}^{-3}(540 \mathrm{~nm})$ and 2.7 $\times 10^{16} \mathrm{~cm}^{-3}(780 \mathrm{~nm})$. Because net acceptor concentration in co-evaporated CZTSe is $\mathrm{p} \approx 2 \times 10^{16} \mathrm{~cm}^{-3}[10]$, high injection effects could also affect initial decay components for $540 \mathrm{~nm}$ excitation [5].

The two-exponential model (with deconvolution of IRF) was applied in data analysis:

$$
I_{P L}=A_{1} \exp \left(-t / \tau_{1}\right)+A_{2} \exp \left(-t / \tau_{2}\right)
$$


where $\mathrm{I}_{\mathrm{PL}}$ is $\mathrm{PL}$ intensity, $\mathrm{t}$ is time, and $\mathrm{A}_{1} / \mathrm{A}_{2}$ are amplitudes of $\tau_{1} / \tau_{2}$ decay components. Lifetimes of the longer decay component were $\tau_{2}=4.4 \mathrm{~ns}$ irrespective if $540 \mathrm{~nm}$ and $780 \mathrm{~nm}$ excitation was used. Lifetimes of the faster decay components were different: $\tau_{1 \_540 \mathrm{~nm}}=0.78 \mathrm{~ns}$ and $\tau_{1 \_780 \mathrm{~nm}}=1.17 \mathrm{~ns}$. The relative amplitude of the faster decay component is larger when $540-\mathrm{nm}$ excitation was used: $A_{1 \_540 \mathrm{~nm}}=88 \%$ and $A_{1 \_} 780 \mathrm{~nm}=70 \%$ of the total decay amplitude, which supports attribution of the first decay component to recombination at the surface or to high-injection effects. Inset in Fig. 1 shows that with $780 \mathrm{~nm}$ excitation lifetimes $\tau_{1} / \tau_{2}$ are approximately constant when excitation intensity is varied from $(1.7-4.0) \times 10^{12}$ photons $\mathrm{cm}^{-2}$ pulse $^{-1}$. This characteristic suggests that when $780 \mathrm{~nm}$ excitation was employed, $\tau_{1}$ in Fig. 1 was largely due to surface recombination. (High injection yields bimolecular decays where lifetime strongly depends on excitation intensity [5].) Because with $540 \mathrm{~nm}$ excitation injection was higher (due to larger $\alpha_{540 \mathrm{~nm}}$ ), $\tau_{1 \_540 \mathrm{~nm}}$ might be affected by bimolecular recombination.

Further, Fig. 1 shows that 1PE TRPL measurement does not completely resolve charge-separation dynamics in polycrystalline PV devices. Decay measured with 540-nm excitation for a device (blue) is similar to that for the polycrystalline film (black). Based on these data, it is not clear what effect surface structures (CdS/CZTSe interface in a PV device vs. bare CZTSe absorber in polycrystalline film) and electronic band structures have on recombination and charge separation. To better differentiate 1PE data for polycrystalline films and PV devices we analyzed time-integrated PL intensity in Fig. 2. 


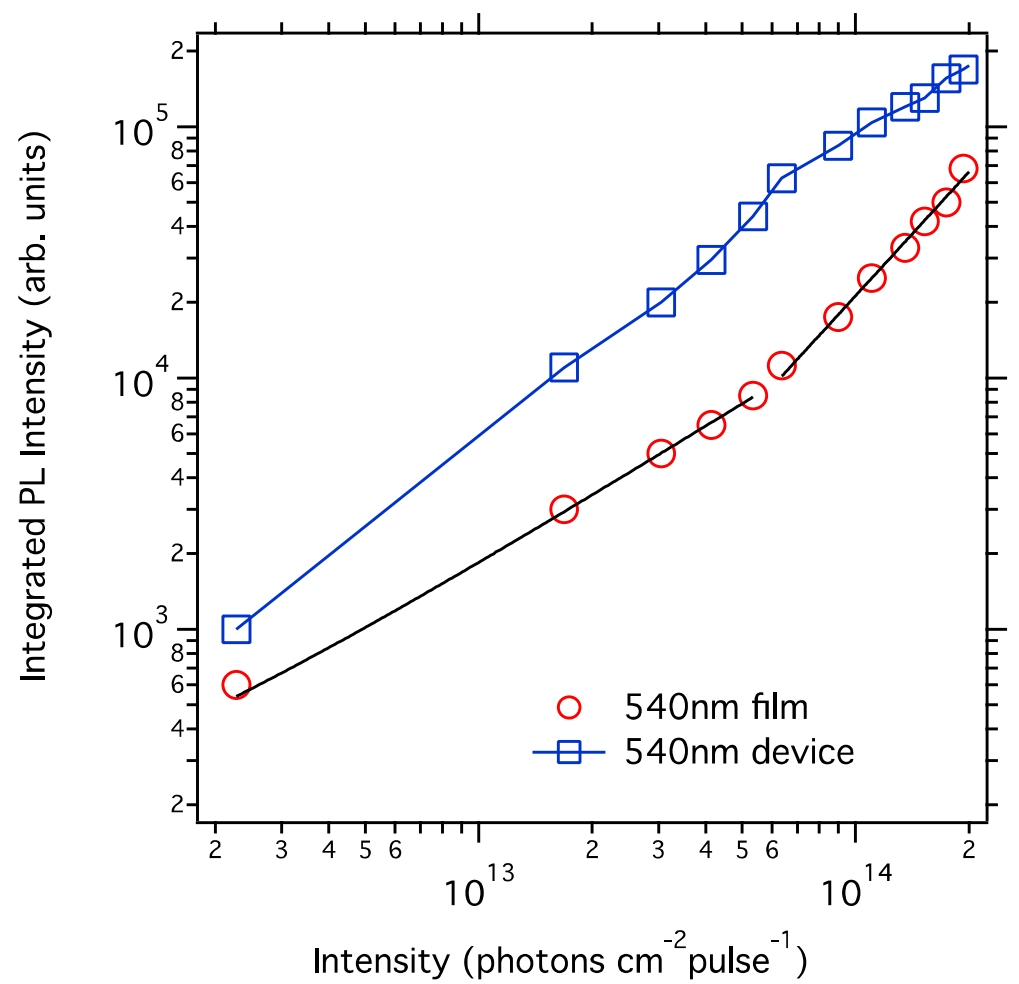

Fig. 2. Integrated 1PE PL intensity dependence for polycrystalline film (red symbols) and PV device (blue symbols). Black solid lines indicate change of slope from $0.90 \pm 0.03$ at low injection to $1.77 \pm 0.02$ at high injection for polycrystalline film sample.

PL intensity, IPL, for a p-type semiconductor is proportional to

$$
I_{P L} \propto B \times(p+\Delta p) \times \Delta n,
$$

where $\mathrm{B}$ is the radiative recombination coefficient, and $\Delta \mathrm{n}=\Delta \mathrm{p}$ are concentrations of photogenerated electrons and holes, respectively. For low injection, $\mathrm{p}>>\Delta \mathrm{p}$ and $\mathrm{I}_{\mathrm{PL}} \propto \Delta \mathrm{n} \propto \mathrm{I}_{\text {laser, }}$ where $\mathrm{I}_{\text {laser }}$ is excitation intensity. For high injection, $\Delta \mathrm{p}>>\mathrm{p}$ and IPL $\propto \Delta n^{2} \propto I_{\text {laser }}{ }^{2}$. These two limiting cases could be distinguished from the slope of the IPL vs. Ilaser graph in Fig. 2 . When $\mathrm{I}_{\text {laser }}=(2.3-53) \times 10^{12}$ photons $\mathrm{cm}^{-2}$ pulse-1, the 
slope is $0.90 \pm 0.03$. Slope increases to $1.77 \pm 0.02$ at high injection, which could indicate transition from low- to high-injection in measurements on polycrystalline film. Intensity-dependent PL characteristics for a PV device are different (Fig. 2, blue symbols), because charge-separation of electron/hole pairs also changes PL intensity and lifetimes. This is further analyzed in Section 3.3.

Next, we estimate surface recombination velocity, S, from the analysis of the first decay component $\tau_{1}$ measured for a polycrystalline film. When laser excitation is absorbed close to the surface, $\mathrm{S}$ could be estimated from the initial slope (i.e., $\left.1 / \tau_{1}\right)$ of the time-resolved data $[22,35]$ :

$$
\frac{1}{\tau_{1}}=\frac{1}{\tau_{B}}+\alpha S .
$$

Eq. (3) was derived to analyze photoconductive decays for silicon [22] and applied to TRPL data for CdTe single crystals, [18] polycrystalline films, [18] and epilayers [35]. When $\alpha \mathrm{S}>>\tau_{\mathrm{B}}{ }^{-1}$, as is the case for direct-bandgap absorbers with large S, Eq. (3) does not allow estimating $\tau_{\mathrm{B}}[18,35]$. (Both terms could be determined for silicon [22].) Below, we show that $\tau_{\mathrm{B}}$ could be measured when electron-hole pairs are created in the bulk of the absorber by employing 2PE.

When $\tau_{1}$ determined with 540-nm and 780-nm excitation (Fig. 1) are used in Eq. (3) assuming $\tau_{\mathrm{B}} \gg>\tau_{1}$ (see Section 3.2), $\mathrm{S}$ could be estimated as $\mathrm{S}=(0.8-2.1) \times$ $10^{4} \mathrm{~cm} \mathrm{~s}^{-1}$. Estimated $\mathrm{S}$ is smaller than that for polycrystalline or single-crystal CdTe $\left(S=(0.5-1.5) \times 10^{5} \mathrm{~cm} \mathrm{~s}^{-1}[18]\right)$, but higher than that for polycrystalline $\mathrm{CuIn}_{1}$ - 
${ }_{x} \mathrm{Ga}_{\mathrm{x}} \mathrm{Se}_{2}$ with $\mathrm{x}=0.3$ (CIGS), where $\mathrm{S}<10^{3} \mathrm{~cm} \mathrm{~s}^{-1}$ [23]. In PV devices, $\mathrm{S}$ could be different due to changes in chemical and electronic structure. In particular, band alignment at the buffer (commonly, CdS) and absorber interface critically changes the interface recombination impact on the device [1]. Therefore, surface recombination velocity $S=(0.8-2.1) \times 10^{4} \mathrm{~cm} \mathrm{~s}^{-1}$ estimated in measurement on polycrystalline film is not necessarily the same as interface recombination velocity in a CdS/CZTSe PV device.

\subsection{Two-photon excitation (2PE) TRPL decays for polycrystalline film}

When ultrafast laser pulses of high intensity, but with photon energy smaller than $E_{g}$, are applied to semiconductors, electron-hole pairs could be created in a two-photon absorption process (Scheme I). The advantage of this approach is that carriers are photogenerated at the focus of the laser beam - which, for thick samples, could be separated from the surface $[24,18,19]$. In the case of $\approx 1.5-\mu \mathrm{m}$ thick absorbers, excitation volume spans all polycrystalline film (Scheme I). Because metal (Mo) layer is present as a substrate for polycrystalline film [6,7], 1560-nm photons that were not absorbed in the first pass could be reflected from the metal and generate additional electron-hole pairs. The reflection coefficient for Mo film at $1560 \mathrm{~nm}$ is $\approx 0.74$ [20]. This value suggests that generation largely happens during the first pass of the 1560-nm laser beam through the absorber. 


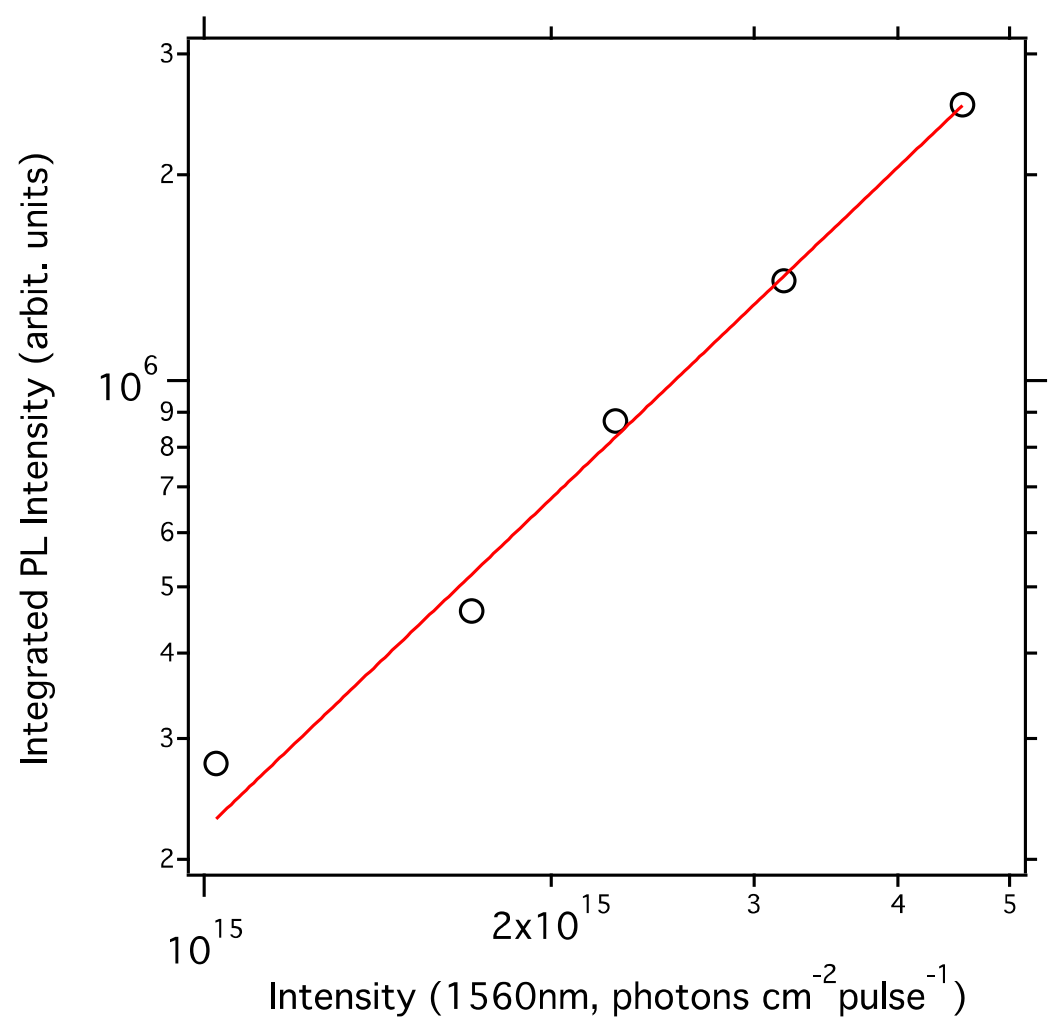

Fig. 3. Integrated PL intensity dependence measured with two-photon excitation (2PE) for CZTSe polycrystalline film.

To verify that one-photon absorption to/from defect bands or discrete states does not significantly contribute to PL signal when $1560 \mathrm{~nm}$ excitation was used, Fig. 3 shows 2PE PL intensity dependence. The slope of this line is $1.61 \pm 0.06$, whereas the corresponding exponent for $1 \mathrm{PE}$ at low injection was $0.90 \pm 0.03$ (Fig. 2). Thus, PL intensity dependence in Fig. 3 agrees with a nonlinear two-photon generation process $[18,24,25]$. (As estimated below, this data was measured under low-injection.) Quantum efficiency spectra for CZTSe PV devices also show that absorption through defect states cannot be large $[6,10,17]$. 


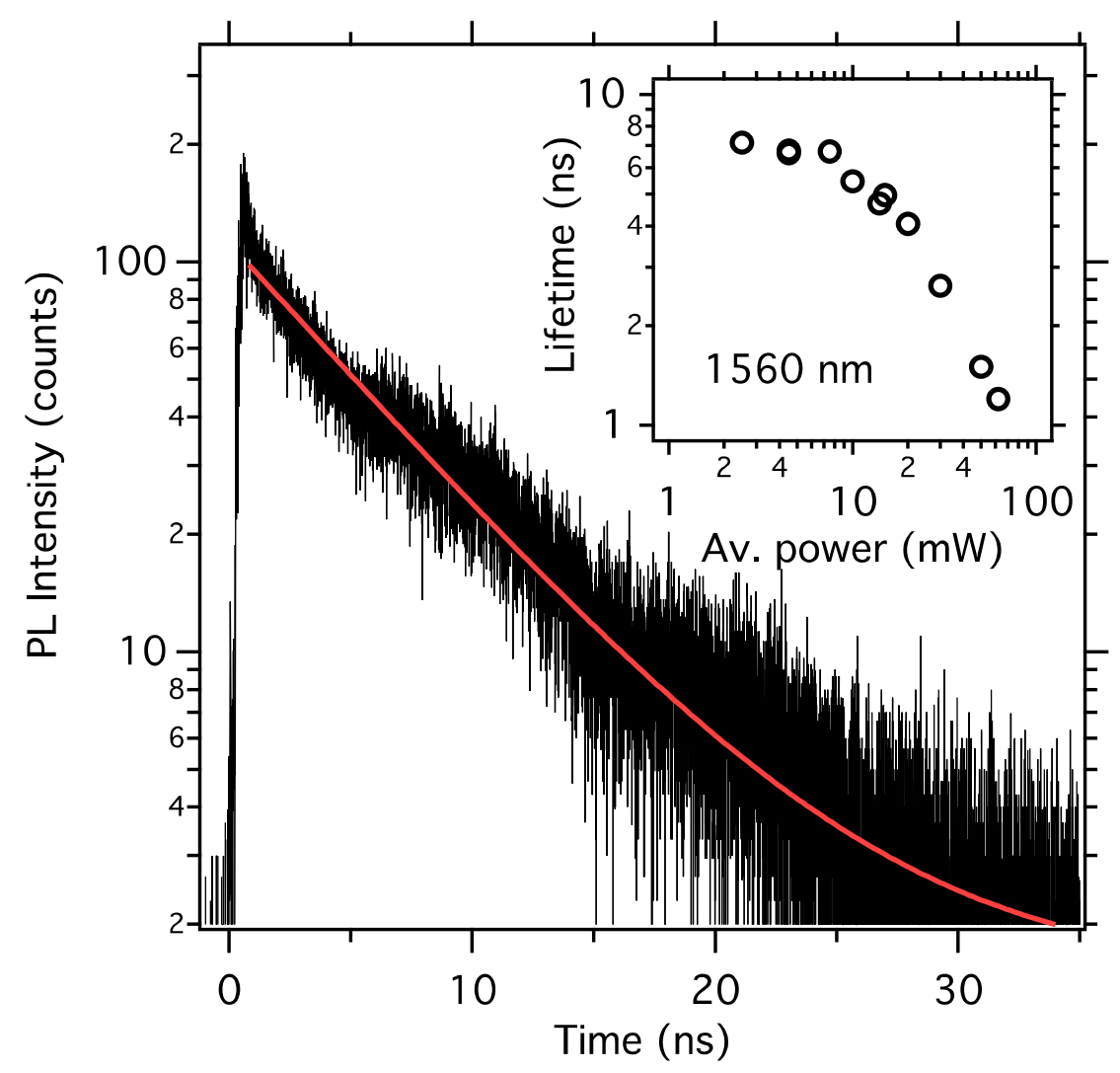

Fig. 4. 2PE TRPL decay measured with excitation intensity $1.0 \times 10^{16}$ photons $\mathrm{cm}^{-2}$ pulse $^{-1}$ (4.5-mW average laser power). Inset shows 2PE TRPL lifetime dependence on excitation intensity.

The excitation beam diameter in this $2 \mathrm{PE}$ measurement is $\approx 0.02 \mathrm{~mm}$.

Relatively large excitation spot allows for lower injection and simplifies data analysis because carrier diffusion effects are significantly reduced [35]. Fig. 4 shows 2PE TRPL decay measured with low excitation intensity of $1.0 \times 10^{16}$ photons $\mathrm{cm}^{-2}$ pulse $^{-1}$. This decay could be described as single-exponential with $\tau_{\mathrm{B}}=7.0 \pm 0.5 \mathrm{~ns}$. Within the uncertainty of the measurement, the lifetime was the same when the polycrystalline film was translated laterally and when the average laser power was decreased to $5.7 \times 10^{15}$ photons $\mathrm{cm}^{-2}$ pulse $\mathrm{e}^{-1}$ or increased to $1.7 \times 10^{16}$ photons $\mathrm{cm}^{-2}$ pulse $^{-1}$. Two-photon absorption coefficient, $\beta$, is not known for kesterites. Many 
semiconductors have $\beta \approx 20 \mathrm{~cm} \mathrm{GW}^{-1}$ [26]. (This value is somewhat uncertain, because $\beta$ also depends on the laser pulse length, and few $\beta$ measurements employed pulses $<1$ ps.) If we assume $\beta=20 \mathrm{~cm} \mathrm{GW}^{-1}, \beta \mathrm{I}=88 \mathrm{~cm}^{-1}$ (where $\mathrm{I}=4.4$ $\mathrm{GWcm}^{-2}$ is excitation peak intensity, which corresponds to $1.0 \times 10^{16}$ photons $\mathrm{cm}^{-2}$ pulse $^{-1}$ and 0.3 -ps pulse length). Based on the estimated $\beta$ I value, much less than $1 \%$ of 1560-nm photons are absorbed in polycrystalline CZTSe, and the injection level is $<10^{15} \mathrm{~cm}^{-3}$, which is an order of magnitude lower than the net acceptor concentration in coevaporated CZTSe $\left(\mathrm{p} \approx 2 \times 10^{16} \mathrm{~cm}^{-3}[10]\right)$.

Because 2PE TRPL decay in Fig. 4 was measured at low injection, it can be described as single-exponential, lifetime is independent of injection (in (5.7-17) $\times$ $10^{15}$ photons $\mathrm{cm}^{-2}$ pulse $^{-1}$ range), and most of the PL signal is collected from the bulk of the absorber, the lifetime determined in this measurement could be regarded as the minority-carrier lifetime (i.e., $\tau_{\mathrm{B}}=7.0 \pm 0.5 \mathrm{~ns}$ ).

As 1560-nm excitation power is increased, decays cease to be singleexponential and the lifetime of the dominant decay component decreases, as illustrated in the inset of Fig. 4. This effect might be related to high injection, albeit accurate injection-level analysis is not possible until kesterite two-photon absorption coefficients are measured and optical path length for 2PE excitation is determined.

Polycrystalline kesterites are disordered semiconductors and their PL emission spectra have been analyzed with models for donor-acceptor pairs (DAP) [27] and electrostatic potential fluctuations $[28,13]$. Such recombination happens by tunneling, the rate of which is very sensitive to the distance between defects; 
therefore, lifetime changes with the injection level. Further, in the case of DAP recombination, PL decays are not exponential and the apparent lifetime decreases when the concentration of defects is increasing [29]. Spectroscopic and injectionlevel recombination analysis, similar to that recently reported for CIGS [30], is not yet possible because, in addition to tunneling recombination, kesterites have strong Shockley-Read-Hall (SRH) recombination due to unknown midgap states [28]. Thus, comparison of TRPL lifetimes for kesterites reported by different groups needs to be done with caution, because recombination mechanisms (SRH, tunneling, surface/interface) could vary for different absorber and device preparations, and could depend on measurement conditions.

Lifetime $\tau_{\mathrm{B}}=7 \mathrm{~ns}$ is relatively short (e.g., corresponding value for CIGS could be as high as $200 \mathrm{~ns}[23,30])$ and could be limited by recombination in the bulk or recombination at grain boundaries. Theory provides guidance about the identity of potential recombination centers in the bulk [31] and at grain boundaries [32]. Spectroscopic analysis of kesterite films and crystals with well-controlled composition is needed to test predictions about the origin of recombination centers. We note that for CZTSe films studied here, surface recombination does not appear to contribute to 2PE TRPL lifetimes, and the inherent complication of 1PE analysis could be avoided. 


\subsection{Two-photon excitation (2PE) TRPL decays for CdS/CZTSe PV device}

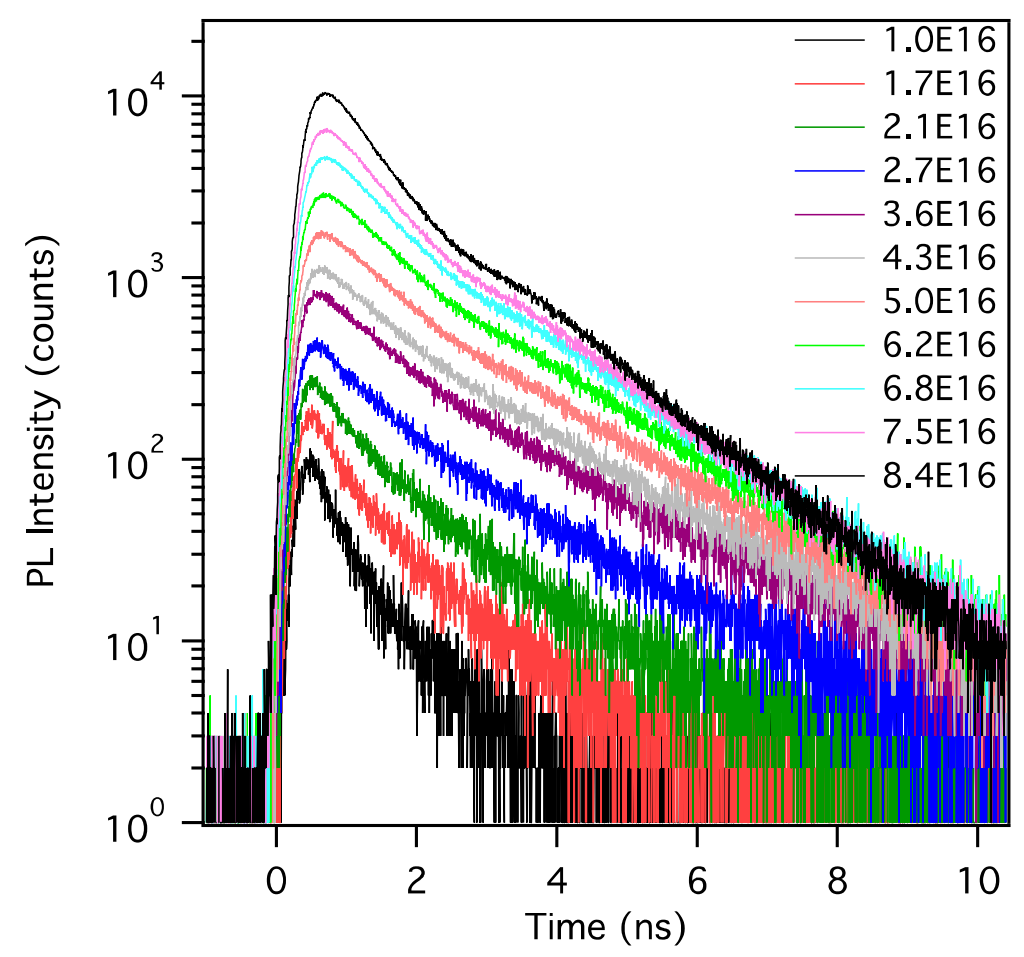

Fig. 5. 2PE TRPL decays for CdS/CZTSe PV device measured with excitation intensity $1.0-8.4 \times 10^{16}$ photons $\mathrm{cm}^{-2}$ pulse-1.

Fig. 5 shows intensity-dependent 2PE TRPL decays measured for a polycrystalline CdS/CZTSe PV device. The absorber for this device corresponds to polycrystalline film studied in Figs. 1 - 4. In section 3.2, we showed that 2PE measurement in this excitation range corresponds to low-injection (estimated as $<10^{15} \mathrm{~cm}^{-3}$ ). The dynamics in Fig. 5 are much faster than corresponding data for polycrystalline film (Fig. 4), which is attributed to charge separation in a PV device. Therefore, 2PE measurement allows unambiguous identification of minority carrier lifetime (2PE measurement on a polycrystalline kesterite film) and observation of 
charge separation dynamics (2PE measurement on a PV device). With 1PE, measurements on kesterite films and devices often yielded similar data [5-17], and therefore physical interpretation of TRPL decays in terms of material and device parameters are somewhat ambiguous.

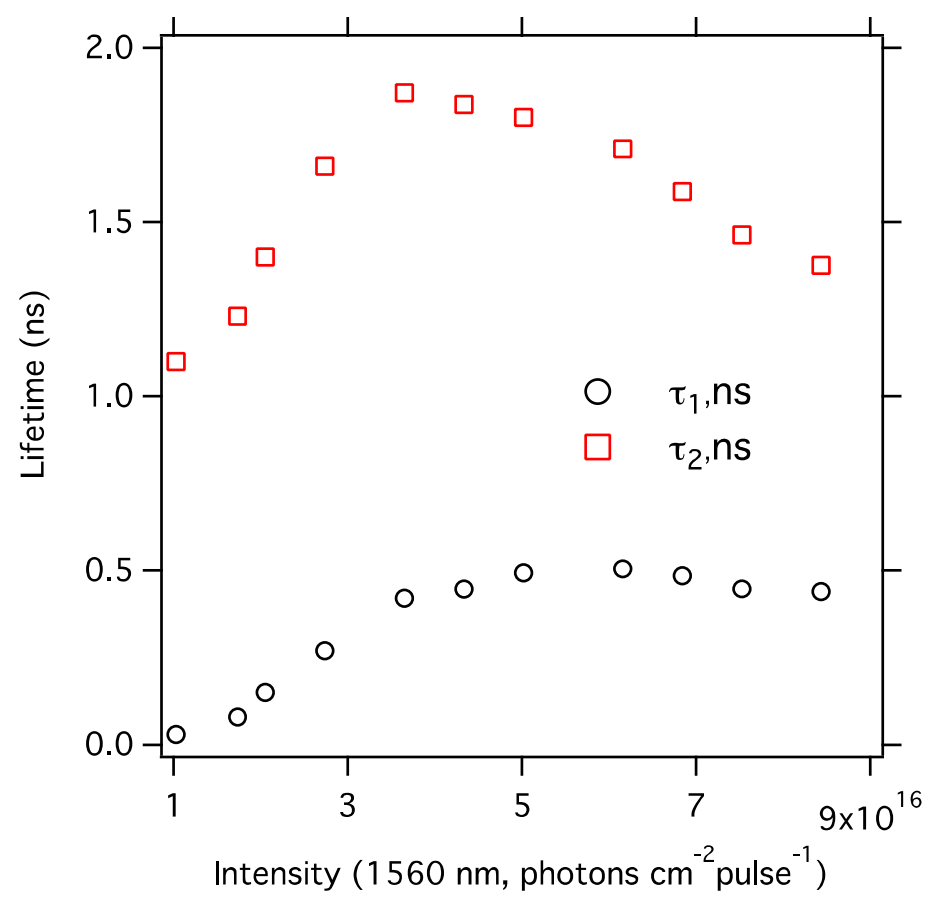

Fig. 6. Lifetimes $\tau_{1}$ and $\tau_{2}$ obtained by fitting data in Fig. 5 to a two-exponential decay model.

2PE TRPL decays for a PV device in Fig. 5 are not single-exponential. Detailed computational analyses of TRPL data for thin film PV devices have been used in order to separate recombination and transport characteristics [33,34]. Twoexponential decay model has been used in computational studies; therefore we also apply this model to the data in Fig. 5. Intensity-dependent lifetimes of the decay components $\tau_{1}$ and $\tau_{2}$ are summarized in Fig. 6 . 
Numerical simulations or TRPL data have shown that the decay component $\tau_{1}$, when measured at lowest injection, usually indicates charge separation (drift) [33,34]. Because $\tau_{B}=7$ ns (Fig. 4) and $\tau_{1}<0.5$ ns (Fig. 6), data suggest that charge separation is faster than recombination. Complex $\tau_{1}$ intensity dependence suggest that charge separation dynamics are affected by the electric field due to photogenerated cariers, and numerical simulations that accurately reflect excitation conditions in 2PE measurement are necessary in order to determine drift and diffusion components of the decay.[33,34] To establish generation parameters for simulations, two-photon absorption coefficient $\beta$ needs to be determined for polycrystalline kesterite absorbers.

The component $\tau_{2}$ also has complex excitation-intensity dependence (Fig. 6). Simulations indicated that $S$ and $\tau_{B}$ change $\tau_{2}$, and, in most cases, $\tau_{2}<\tau_{B}[33,34]$. In agreement with earlier computational studies, lifetime $\tau_{2}$ measured for devices (Fig. $6, \tau_{2}=1-2 \mathrm{~ns}$ ) is about four times shorter than $\tau_{\mathrm{B}}$ measured for films (Fig. $4, \tau_{\mathrm{B}}=$ $7 n s)$.

Thus, 2PE measurements on polycrystalline films appear to provide better assessment for $\tau_{\mathrm{B}}$. For TRPL data measured on PV devices, without detailed computational analysis, it is not possible to separate effects due to charge separation and recombination, regardless if $1 \mathrm{PE}$ or $2 \mathrm{PE}$ excitation conditions are used. 1PE TRPL measurements on polycrystalline films are dominated by surface recombination, whereas surface recombination effects on $2 \mathrm{PE}$ data are reduced due to the bulk generation profile provided by this measurement. 


\section{Summary}

We have shown that combination of 1PE and 2PE TRPL analysis applied to polycrystalline thin films and PV devices allows determination of surface recombination velocity, bulk lifetime, and charge-separation dynamics at the pn junction. For state-of-the-art vacuum-deposited CZTSe absorbers, we find S = 0.8$2.1 \times 10^{4} \mathrm{~cm} \mathrm{~s}^{-1}$ and $\tau_{\mathrm{B}}=7 \mathrm{~ns}$.

\section{Acknowledgment}

This work was supported by the U.S. Department of Energy under Contract No. DE-AC36-08-G028308 with the National Renewable Energy Laboratory. 


\section{References}

[1] S. Siebentritt, Why are kesterite solar cells not 20\% efficient?, Thin Solid Films 535 (2013) 1-4.

[2] A. Polizzotti, I. L. Repins, R. Noufi, S.-H. Wei, and D. B. Mitzi, The state and future prospects of kesterite photovoltaics, Energy \& Environmental Science 6 (2013), 3171-3182.

[3] I. L. Repins, H. Moutinho, S. G. Choi, A. Kanevce, D. Kuciauskas, P. Dippo, C. L. Beall, J. Carapella, C. DeHart, B. Huang, and S. H. Wei, Indications of short minoritycarrier lifetime in kesterite solar cells, Journal of Applied Physics 114 (2013) 084507.

[4] R. K. Ahrenkiel, N. Call, S. W. Johnston, and W. K. Metzger, Comparison of techniques for measuring carrier lifetime in thin-film and multicrystalline photovoltaic materials, Solar Energy Materials and Solar Cells 94 (2010) 21972204.

[5] 0. Gunawan, T. K. Todorov, and D. B. Mitzi, Loss mechanisms in hydrazineprocessed $\mathrm{Cu}_{2} \mathrm{ZnSn}(\mathrm{Se}, \mathrm{S})_{4}$ solar cells, Applied Physics Letters 97 (2010) 233506.

[6] I. L. Repins, C. Beall, N. Vora, C. DeHart, D. Kuciauskas, P. Dippo, B. To, J. Mann, W.-C. Hsu, A. Goodrich, and R. Noufi, Co-evaporated $\mathrm{Cu}_{2} \mathrm{ZnSnSe}_{4}$ films and devices, Solar Energy Materials and Solar Cells 101 (2012) 154-159.

[7] I.L. Repins, J.V. Li, A. Kanevce, C.L. Perkins, K.X. Steirer, J. Pankow, G. Teeter, D. Kuciauskas, C. Beall, C. Dehart, J. Carapella, B. Bob, J.-S. Park, S.-H. Wei, Thin Solid Films, In Press: DOI: 10.1016/j.tsf.2014.09.028 (2014).

[8] D. A. R. Barkhouse, O. Gunawan, T. Gokmen, T. K. Todorov, and D. B. Mitzi, Device characteristics of a $10.1 \%$ hydrazine-processed Cu2ZnSn(Se,S $) 4$ solar cell, Progress in Photovoltaics: Research and Applications 20 (2012) 6-11.

[9] I. L. Repins, M. J. Romero, J.V. Li, S.-H. Wei, D. Kuciauskas, C.-S. Jiang, C. Beall, C. DeHart, J. Mann, W.-C. Hsu, G. Teeter, A. Goodrich, and R. Noufi, Kesterite successes, ongoing work, and challenges: a perspective from vacuum deposition, IEEE Journal of Photovoltaics 3 (2013) 439-445.

[10] J. V. Li, D. Kuciauskas, M. R. Young, and I. L. Repins, Effects of sodium incorporation in Co-evaporated $\mathrm{Cu}_{2} \mathrm{ZnSnSe}_{4}$ thin-film solar cells, Applied Physics Letters 102 (2013) 163905. 
[11] T. K. Todorov, J. Tang, S. Bag, O. Gunawan, T. Gokmen, Y. Zhu, and D.B. Mitzi, Effects of sodium incorporation in Co-evaporated $\mathrm{Cu}_{2} \mathrm{ZnSnSe}_{4}$ thin-film solar cells, Advanced Energy Materials 3 (2013) 34-38.

[12] L. Guo, Y. Zhu, O. Gunawan, T. Gokmen, V. R. Deline, S. Ahmed, L. T. Romankiw, and $\mathrm{H}$. Deligianni, Electrodeposited $\mathrm{Cu}_{2} \mathrm{ZnSnSe}_{4}$ thin film solar cell with $7 \%$ power conversion efficiency, Progress in Photovoltaics: Research and Applications 22 (2014) 58-68.

[13] T. Gokmen, O. Gunawan, T. K. Todorov, and D. B. Mitzi, Band tailing and efficiency limitation in kesterite solar cells, Applied Physics Letters 103 (2013) 103506.

[14] G. Brammertz, M. Buffière, Y. Mevel, Y. Ren, A. E. Zaghi, N. Lenaers, Y. Mols, C. Koeble, J. Vleugels, M. Meuris, and J. Poortmans, Correlation between physical, electrical, and optical properties of $\mathrm{Cu}_{2} \mathrm{ZnSnSe}_{4}$ based solar cells, Appl. Phys. Lett. 102 (2013) 013902.

[15] H. Sugimoto, C. Liao, H. Hiroi, N. Sakai, and T. Kato, Lifetime improvement for high efficiency $\mathrm{Cu}_{2} \mathrm{ZnSnS}_{4}$ submodules, in Proceedings 39th IEEE PVSC (2013) 32083211.

[16] M. Buffière, G. Brammertz, A. El Mel, N. Lenaers, Y. Ren, A. E. Zaghi, Y. Molsa, C. Koebled, J. Vleugelsb, M. Meurisa, and J. Poortmans, Recombination stability in polycrystalline $\mathrm{Cu}_{2} \mathrm{ZnSnSe}_{4}$ thin films, in Proceedings 39th IEEE PVSC (2013) 19411944.

[17] G. Brammertz, M. Buffière, S. Oueslati, H. ElAnzeery, K. Ben Messaoud, S. Sahayaraj, C. Köble, M. Meuris, and J. Poortmans, Characterization of defects in 9.7\% efficient $\mathrm{Cu}_{2} \mathrm{ZnSnSe}_{4}$-CdS-ZnO solar cells, Applied Physics Letters 103 (2013) 163904.

[18] D. Kuciauskas, A. Kanevce, J. M. Burst, J. N. Duenow, R. Dhere, D. S. Albin, D. H. Levi, and R. K. Ahrenkiel, Minority carrier lifetime analysis in the bulk of thin-film Absorbers using subbandgap (two-photon) excitation, IEEE Journal of Photovoltaics 3 (2013) 1319-1324.

[19] J. Ma, D. Kuciauskas, D. Albin, R. Bhattacharya, M. Reese, T. Barnes, J. V. Li, T. Gessert, and S.-H. Wei, Minority carrier lifetime analysis in the bulk of thin-film absorbers using subbandgap (two-photon) excitation, Physical Review Letters 111 (2013) 067402.

[20] S. G. Choi, H. Y. Zhao, C. Persson, C. L. Perkins, A. L. Donohue, B. To, A. G. Norman, J. Li, and I. L. Repins, Dielectric function spectra and critical-point energies of $\mathrm{Cu}_{2} \mathrm{ZnSnSe}_{4}$ from 0.5 to $9.0 \mathrm{eV}$, Journal of Applied Physics 111 (2012) 033506. 
[21] R. Haight, A. Barkhouse, O. Gunawan, B. Shin, M. Copel, M. Hopstaken, and D. B. Mitzi, Band alignment at the $\mathrm{Cu}_{2} \mathrm{ZnSn}\left(\mathrm{S}_{\mathrm{x}} \mathrm{Se}_{(1-\mathrm{x})}\right)_{4} / \mathrm{CdS}$ interface, Applied Physics Letters 98 (2011) 253502.

[22] R. K. Ahrenkiel and S. W. Johnston, An optical technique for measuring surface recombination velocity, Solar Energy Materials and Solar Cells 93 (2009) 645-649; R. K. Ahrenkiel and J. Dashdorj, Interface recombination velocity measurement by a contactless microwave technique, Journal of Vacuum Science \& Technology B 22 (2004) 2063-2067.

[23] W. K. Metzger, I. L. Repins, M. Romero, P. Dippo, M. Contreras, R. Noufi, and D. Levi, Recombination kinetics and stability in polycrystalline $\mathrm{Cu}(\mathrm{In}, \mathrm{Ga}) \mathrm{Se}_{2}$ solar cells, Thin Solid Films 517 (2009) 2360-2364.

[24] E. S. Barnard, E. T. Hoke, S. T. Connor, J. R. Groves, T. Kuykendall, Z. Yan, E. C. Samulon, E. D. Bourret-Courchesne, S. Aloni, P. J. Schuck, C. H. Peters, and B. E. Hardin, Probing carrier lifetimes in photovoltaic materials using subsurface twophoton microscopy, Scientific Reports 3 (2013) 1-9.

[25] S. Juršėnas, S. Miasojedovas, A. Žukauskas, B. Lucznik, I. Grzegory, and T. Suski, Carrier recombination and diffusion in GaN revealed by transient luminescence under one-photon and two-photon excitations, Applied Physics Letters 89 (2006) 172119.

[26] V. Nathan, A. H. Guenther, and S. S. Mitra, Review of multiphoton absorption in crystalline solids, Journal of the Optical Society of America B 2 (1985) 294-316.

[27] F. Luckert, D. I. Hamilton, M. V. Yakushev, N. S. Beattie, G. Zoppi, M. Moynihan, I. Forbes, A. V. Karotki, A. V. Mudryi, M. Grossberg, J. Krustok, and R. W. Martin, Optical properties of high quality $\mathrm{Cu}_{2} \mathrm{ZnSnSe}_{4}$ thin films, Applied Physics Letters 99 (2011) 062104.

[28] M. J. Romero, H. Du, G. Teeter, Y. Yan, and M. M. Al-Jassim, Comparative study of the luminescence and intrinsic point defects in the kesterite $\mathrm{Cu}_{2} \mathrm{ZnSnS}_{4}$ and chalcopyrite $\mathrm{Cu}(\mathrm{In}, \mathrm{Ga}) \mathrm{Se}_{2}$ thin films used in photovoltaic applications, Physical Review B 84 (2011) 165324.

[29] D. G. Thomas, J. J. Hopfield, and W. M. Augustyniak, Kinetics of radiative recombination at randomly distributed donors and acceptors, Physical Review 140 (1965) A202-A220.

[30] D. Kuciauskas, J. V. Li, M. A. Contreras, J. Pankow, P. Dippo, M. Young, L. M. Mansfield, R. Noufi, and D. Levi, Charge carrier dynamics and recombination in graded band gap $\mathrm{CuIn}_{(1-\mathrm{x})} \mathrm{Ga}_{\mathrm{x}} \mathrm{Se}_{2}$ polycrystalline thin-film photovoltaic solar cell absorbers, Journal of Applied Physics 114 (2013) 154505. 
[31] S. Chen, A. Walsh, X.-G. Gong, and S.-H. Wei, Classification of lattice defects in the kesterite $\mathrm{Cu}_{2} \mathrm{ZnSnS}_{4}$ and $\mathrm{Cu}_{2} \mathrm{ZnSnSe}_{4}$ earth-abundant solar cell absorbers, Advanced Materials 25 (2013) 1522-39.

[32] W.-J. Yin, Y. Wu, S.-H. Wei, R. Noufi, M. M. Al-Jassim, and Y. Yan, Engineering grain boundaries in $\mathrm{Cu}_{2} \mathrm{ZnSnSe}$ for better cell performance: a first-principle study, Advanced Energy Materials, 4 (2014) 1300712.

[33] A. Kanevce, D. Kuciauskas, T. A Gessert, D. H. Levi, and D. S. Albin, Impact of Interface on time resolved photoluminescence (TRPL) Decays in CdTe solar cells (numerical simulation analysis), in Proc. 38 IEEE PVSC (2012), pp. 848-853.

[34] A. Kanevce, D. H. Levi, and D. Kuciauskas, The role of drift, diffusion, and recombination in time-resolved photoluminescence of CdTe solar cells determined through numerical simulation, Progress in Photovoltaics: Research and Applications, 22 (2013) 1138-1146.

[35] D. Kuciauskas, S. Farrell, P. Dippo, J. Moseley, H. Moutinho, J. V. Li, A. M. Allende Motz, A. Kanevce, K. Zaunbrecher, T.A. Gessert, D.H. Levi, W.K. Metzger, E. Colegrove, and S. Sivananthan, Charge-carrier transport and recombination in heteroepitaxial CdTe, Journal of Applied Physics 116 (2014) 123108. 

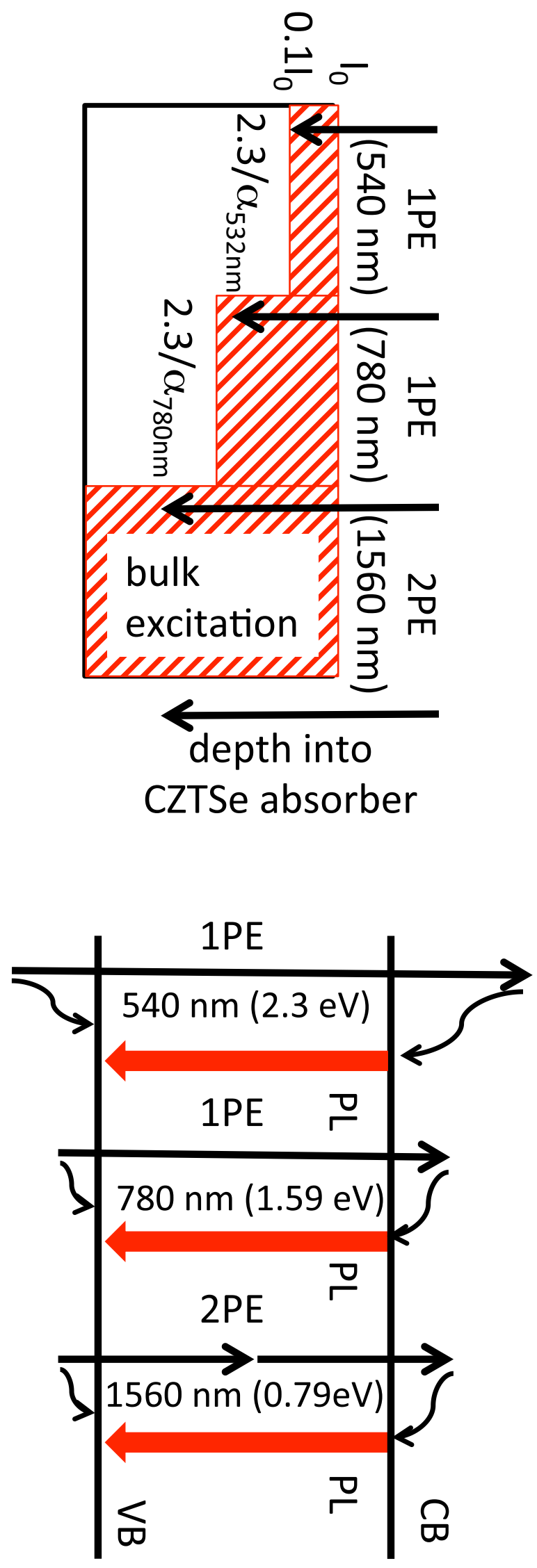